\title{
O indivíduo renal crônico e as demandas de atenção*
}

\author{
The person with renal chronic disease and caring demands \\ Personas con enfermedad renal cronica y las demandas por atención
}

\section{Carla Klava dos Reis', Ednêis de Brito Guirardello", Claudinei José Gomes Campos" \\ 'Hospital Estadual de Sumaré. Sumaré, SP \\ "Universidade Estadual de Campinas. Faculdade de Ciências Médicas. Campinas, SP}

\begin{abstract}
Submissão: 20/07/2007
Aprovação: 28/03/2008

\section{RESUMO}

Objetivou-se analisar as diferentes fontes de demanda de atenção vivenciadas por oito mulheres com insuficiência renal crônica, em tratamento hemodialítico de um hospital universitário do interior do Estado de São Paulo. Trata-se de um estudo Qualitativo, por meio de uma entrevista semi-estruturada. A análise foi descritiva por meio da técnica de análise de conteúdo. Dentre as demandas destacam-se: ausência de perspectiva Quanto ao futuro; morte como possibilidade iminente; perda de autonomia e relação de dependência com a máQuina. Há ainda a responsabilidade materna e a preocupação com o colega Que vivencia tal problema. Tais demandas podem dificultar para a pessoa em direcionar atenção para situações importantes, como o tratamento e a busca por uma melhor Qualidade de vida.
\end{abstract}

Descritores: Insuficiência renal crônica; Hemodiálise; Atenção.

\begin{abstract}
The objective was to analyse the sources of attentional demands experienced by eight women with renal chronic disease undergone to hemodialisys treatment in a university hospital at the State of São Paulo. This is a Qualitative study achieved by means of a semi-structured interview. The analysis was based on a content analysis technique. Among the demands the most important were: lack of perspective toward the future; death as an imminent possibility; lost of autonomy and dependence with the machine. Also important were maternal responsibility and the worry with friends that lived the same problem. These demands contribute to decrease the capacity to focus attention to important situations related to the treatment and the search for a better Quality of life.
\end{abstract}

Descriptors: Renal insufficiency; Hemodialysis; Attention.

\section{RESUMEN}

El objetivo es analizar las fuentes de demanda de atención vividas por ocho mujeres con insuficiencia renal crónica, en hemodiálisis en un hospital universitario de una ciudad de São Paulo. Es un estudio cualitativo donde fueron realizadas entrevistas semi estructuradas. El análisis fue descriptivo a través de la técnica de análisis de contenido. Entre las demandas se destacan: ausencia de perspectivas con relación al futuro; muerte como posibilidad inminente; pérdida de autonomía y la situación de dependencia con la máouina; la responsabilidad materna y la preocupación con el colega Que vive problema similar. Estas demandas pueden dificultar para la persona en dirigir la atención para situaciones importantes, tales como el tratamiento y la búsqueda por una mejor calidad de vida.

Descriptores: Insuficiencia renal crónica; Hemodiálisis; Atención. 


\section{INTRODUÇÃO}

A Insuficiência Renal Crônica (IRC) é uma enfermidade Que, além de trazer conseqüências físicas ao indivíduo Que a vivencia, traz prejuízos psicológicos e altera o seu cotidiano, sendo caracterizada também como um problema social, Que interfere no papel Que esse indivíduo desempenha na sociedade. Então, estabelece-se um longo processo de adaptação a essa nova condição, no Qual o indivíduo precisa identificar meios para lidar com o problema renal e com todas as mudanças e limitações Que o acompanham.

Em janeiro de 2004, havia 59.153 pacientes em tratamento dialítico, sendo Que 89,25\% (52.794 pacientes) estavam especificamente em tratamento de hemodiálise ${ }^{(1)}$. Já o censo de 2005 mostra Que há 65.121 pacientes em tratamento dialítico no Brasil, destes, 57.988 em tratamento hemodialítico ${ }^{(2)}$.

A IRC é uma enfermidade Que compromete a função renal, incapacitando a manutenção da homeostasia interna do organismo ${ }^{(3)}$. Como opções de tratamento têm-se o transplante renal e os processos dialíticos, dentre eles a hemodiálise, a diálise peritoneal intermitente (DPI), a diálise peritoneal ambulatorial contínua (CAPD) e a diálise peritoneal automática (DPA), cujo objetivo é manter a homeostase do organismo e proporcionar uma melhor Qualidade de vida ao indivíduo ${ }^{(4)}$.

O tratamento de hemodiálise, na maioria das vezes, gera frustração e limitações, uma vez Que é acompanhado de diversas restrições, dentre elas a manutenção de uma dieta específica associada às restrições hídricas e a modificação na aparência corporal em razão da presença do cateter para acesso vascular ou da fístula artériovenosa.

A necessidade de se adaptar a novas rotinas impostas pelo tratamento, bem como atender objetivos e propósitos no seu cotidiano, constituem-se em fontes de demandas de atenção para esses pacientes, exigindo dos mesmos um aumento da capacidade de direcionar atenção (CDA) para aspectos importantes do tratamento.

\section{Referencial Teórico: Atenção e Demandas de Atenção}

De acordo com o referencial teórico de atenção e demandas de atenção descrito por Kaplan e Kaplan ${ }^{(5)}$ e desenvolvido por Cimprich $^{(6-8)}$ há Quatro conceitos fundamentais: a) capacidade de direcionar atenção (CDA), b) demandas de atenção, c) fadiga de atenção e d) atividades para manter ou recuperar a CDA.

A capacidade para direcionar atenção (CDA) refere-se a um tipo de atenção voluntária ou seletiva Que requer esforço mental para se manter. Envolve o uso de mecanismos neurais inibitórios para focar a mente no Que é significante (mas nem sempre interessante) para a situação, bloqueia distrações menos relevantes, estímulos competitivos e preocupações Que atuam como demanda de atenção dirigida ${ }^{(6)}$.

Demandas de atenção referem-se aos fatores Que aumentam as exigências para direcionar atenção, ou seja, levam ao aumento do uso da CDA (9), e do esforço mental, podendo acarretar fadiga de atenção.

A fadiga de atenção é resultante de uma capacidade reduzida de direcionar atenção, caracterizada pela diminuição da capacidade de se concentrar e de manejar as atividades diárias. A fadiga de atenção pode ter efeitos, inclusive, no manejo do autocuidado ${ }^{(10)}$. Então, o indivíduo deve se voltar para atividades de manutenção, ou seja, reduzir ou limitar as demandas de atenção, ou de recuperação da CDA. Isto constitui o último conceito do referencial teórico denominado de conservação e recuperação da $C D A$. Limitou-se a examinar neste estudo as demandas de atenção.

\section{OBJETIVO}

Analisar as diferentes fontes de demanda de atenção vivenciadas pelos pacientes com IRC, submetidos ao tratamento de hemodiálise.

\section{MÉTODO}

Por se tratar da análise das demandas de atenção Que os doentes renais em hemodiálise vivenciam no seu tratamento, buscando os significados atribuídos por eles próprios, a metodologia Qualitativa mostrou-se a mais adequada. O método Qualitativo é definido como um método de pesquisa indutivo, holístico, êmico, subjetivo e orientado para o processo, visando compreender, descrever e desenvolver teorias relativas a fenômenos ${ }^{(1)}$.

A peseuisa foi realizada no Centro Integrado de Nefrologia (CIN) de um hospital de ensino do interior do Estado de São Paulo, Brasil.

A população do estudo compreendeu todos os pacientes adultos com IRC em programa de hemodiálise. Para a amostra, consideraramse os pacientes Que atenderam aos critérios de inclusão como: a) idade igual ou superior a 18 anos; b) consentir em participar do estudo de forma voluntária e c) estar apto para entender as Questões formuladas no roteiro de entrevista.

Para a seleção da amostra, utilizou-se a técnica "bola de neve" ou reação em cadeia $^{(12)}$. No entanto, em alguns momentos, a seleção da amostra foi intencional, desencadeada pela convivência da peseuisadora com os sujeitos da unidade e pela possibilidade dessas pessoas fornecerem dados ricos à pesQuisa em decorrência de sua vivência.

A coleta de dados deu-se por meio da ficha de dados de identificação e da entrevista semi-estruturada, contendo Questões Que abordam fatores de demandas relacionados aos domínios: ambiente físico, afetivo, comportamental e de informação ${ }^{(13)}$.

O domínio afetivo refere-se à vida afetiva, às emoções, às preocupações, aos medos enfrentados pelas pessoas, além de outros sentimentos negativos e positivos. O domínio comportamental diz respeito aos fatores biopsicossociais ou situações naturais, como limitações impostas pela doença, normas sociais, expectativas, mudanças no estilo de vida Que interferem nas ou restringem as decisões e as preferências das pessoas.

O domínio ambiente físico refere-se a fatores do ambiente externo Que causam à pessoa o uso de um esforço excessivo, incluindo também objetos, tamanho e distância, além de condições climáticas. lá o domínio de informação refere-se a fatores Que interferem com a percepção e interpretação da informação, tornandoa inadequada e insuficiente.

Para a coleta de dados, obteve-se aprovação do projeto pelo Comitê de Ética em PesQuisa da instituição. Previamente à coleta, realizou-se uma abordagem inicial à população e ao serviço, com o objetivo de se estabelecer uma aproximação da peseuisadora com 
o ambiente, com os profissionais, com o procedimento de hemodiálise e também com os indivíduos submetidos ao tratamento. Essa etapa é importante, pois a relação existente entre aquele Que busca o conhecimento do fenômeno e o fenômeno propriamente dito é crucial para o estudo das experiências vivenciadas pelo ser humano ${ }^{(14)}$.

As entrevistas foram gravadas em fita cassete, posteriormente transcritas literalmente e estudadas por meio da técnica de análise de conteúdo.

Dessa forma, o procedimento de análise dos dados seguiu as etapas de leitura flutuante de todas as entrevistas, seguida da leitura exaustiva do material, em Que se buscaram as unidades de análise, Que compreenderam as diversas demandas de atenção vivenciadas pelos indivíduos.

\section{RESULTADOS E DISCUSSÃO}

A amostra constituiu-se de oito mulheres, com idades entre 19 e 53 anos, Quatro solteiras, duas casadas e duas viúvas, sendo a maioria com o ensino fundamental incompleto. O tempo transcorrido desde o estabelecimento do diagnóstico de insuficiência renal variou de um ano até 33 anos e o tempo de tratamento de hemodiálise variou de 10 meses até 23 anos.

Com relação às demandas apontadas pelos pacientes, essas foram agrupadas nos diferentes domínios afetivo, comportamental, ambiente físico e informação, definidos a priori ${ }^{(13)}$.

\section{Domínio Afetivo}

A reação frente ao diagnóstico do problema renal faz emergir sentimentos de medo pelo desconhecimento da doença, incerteza Quanto ao futuro e pensar na possibilidade de morte, além do mecanismo de defesa "negação". É difícil aceitar a existência do agravo à saúde e, neste momento, o indivíduo pode lançar mão de mecanismos de defesa inconscientes para lidar com a angústia da realidade de estar com uma doença grave ou a necessidade de um tratamento invasivo. É importante dar atenção especial a esses momentos, pois o próprio uso do mecanismo de defesa sinaliza Que o paciente não está conseguindo, neste instante, lançar mão de outros mecanismos adaptativos de cunho consciente para lidar com a carga de ansiedade Que esta situação está lhe impondo(15).

Também eu nem sabia que existia isso. Aí eu entrei e não aceitava de jeito nenhum. Eu abandonei a casa, filho, não Queria saber de viver (...) Não aceitava de jeito nenhum porQue na minha família ninguém tem, né, nunca apareceu isso... aí... eu não pensava em me matar, mas eu pensava em morrer aos pouquinhos.... (E4).

O processo de aceitação da doença renal foi acompanhado de conflitos, medo e incerteza, tais como sentimentos de tristeza, revolta, isolamento social, abandono das suas responsabilidades de mãe e desesperança pelo convívio com uma doença grave e Que pode levá-la à morte.

A desesperança engloba a ausência de perspectivas Quanto ao futuro e sentimentos de tristeza e solidão, Que emergem pelo fato da cura estar distante da realidade daquele indivíduo. É difícil elaborar planos e ter expectativas Quanto ao futuro, justamente por frustrações anteriores e por considerar que a ausência de planos torna a vida menos sofrida, pois caso estes não sejam alcançados não haverá frustração.

Tais sentimentos foram identificados com maior intensidade naQueles indivíduos com idade mais avançada e que vivenciam a doença renal há mais tempo, sendo Que a impossibilidade de realizar o transplante acentua esse sentimento. Em contrapartida, os mais jovens, mesmo Que com alguns anos de doença renal elaboram planos e tem expectativas Quanto ao futuro.

...não existe expectativa. Eu espero viver cada dia até quando me for possível viver. Não tenho... expectativa de ficar curada. Não. Então... a única coisa pra Quem tá doente é Querer ficar curada, né!!! Essa expectativa não existe na minha vida (EI).

Não ter expectativas Quanto ao futuro ou estar impossibilitado de planejar, de sonhar ou não se permitir sonhar pela realidade Que enfrenta, faz com Que o ser humano experiencie a brutalização da essência humana, a desumanização ${ }^{(16)}$.

A morte como possibilidade iminente pode estar presente no dia-a-dia, além da reflexão sobre a morte ser mais freqüente em comparação com uma pessoa sadia. O bem-estar é instável, então complicações podem ocorrer inesperadamente, o Que requer da pessoa um aumento da CDA decorrente da sobrecarga de sentimentos negativos, ao mesmo tempo em Que surgem preocupações Quanto às suas responsabilidades de chefe de família e até mesmo Quanto ao seu papel de mãe.

...porque antes eu me sentia... poxa eu tenho saúde, sou uma pessoa saudável, nem pensava assim Que ia acontecer alguma coisa, de morrer e agora hoje em dia eu fico preocupada, né... a Qualquer momento eu posso morrer e aí como é que fica? (EI).

...porque de vez em Quando... você sabe que está doente... sabe Que não tem nenhuma perspectiva de... parece Que está esperando a morte porQue não tem perspectiva de melhorar, não posso mais entrar na fila do transplante porQue eu tô com aneurisma e não pode fazer transplante. E esse aneurisma parece até que é um punhal na sua cabeça... a QualQuer hora pode morrer, né... então... Quer dizer, fica pensando... (EI).

A responsabilidade materna emergiu como uma fonte de demanda, já Que todas eram mulheres e, algumas, mães. A preocupação com os filhos dependentes foi um dos motivos para o adiamento de um transplante, por se tratar de um procedimento complexo e com riscos. O medo da morte também foi identificado, já Que há a preocupação de não haver outra pessoa Que possa cuidar de seus filhos.

... tem muita gente aqui Que faz hemodiálise e fizeram transplante e quase morreram... é... e eu penso nos meus pequenos, por isso que eu não Quero fazer transplante agora (E4).

Que ia morrer... ia morrer no hospital sozinha, sem ver meus filhos. Pavor, né... e aí amanhã vão saber notícias que 'sua mãe está morta' e aí como vai ser? (EI).

A preocupação e o apego aos filhos dão sentido à vida dessas 
mães, um motivo para continuar lutando e enfrentando as dificuldades do tratamento. Este fato nos remete às Questões existencialistas do ser, em que somente aqueles que conseguem dar um sentido ao seu sofrimento sobrevivem às mais difíceis situações ${ }^{(17)}$.

... Quando eu fiquei aí (internada) os médicos não me dava vida. Chamaram minha família toda e 'Olha, não tem vida, porQue do jeito Que ela tá, ela não vai agüentar'. É... eu passei... eu agüentei, então... vou agüentar mais um pouco até (...) meu filho hoje tá com treze anos, ele já entende as coisas, né... mas ela tem só cinco anos. Então Quando eu venho pra cá ela fica chorando, ela não Quer Que eu venha. Eu não sei o que Que ela pensa, se chega nela e pergunta ela não responde... só que ela não quer Que eu venha pra cá, né... aí eu penso mais nela, na pequena no que nele (E4).

O enfermeiro deve reconhecer a responsabilidade materna como uma fonte de demanda de atenção para essas mulheres, pois dificuldades na família podem interferir no tratamento e valorizar tal preocupação favorece um vínculo de confiança. Faz-se também importante que o enfermeiro atue junto à equipe interdisciplinar, visando minimizar essas fontes de demanda.

\section{Domínio Comportamental}

As fontes de demandas de atenção relacionadas às limitações impostas pela doença, compreendem as restrições alimentar e hídrica, falta de lazer e incapacidade para o trabalho.

As restrições alimentar e hídrica são fundamentais para o sucesso do tratamento e para o bem-estar do indivíduo, mas podem ser fonte de frustração, por modificar hábitos do cotidiano e impor diversas privações. Considerando a alimentação como parte da cultura e individual para cada sociedade, há todo um simbolismo relacionado à alimentação Que difere de uma sociedade para outra, pois varia de acordo com a cultura, com os valores e crenças.

A gente acaba comendo... a gente acaba bebendo até demais,... se fala 'não, é proibido, mas eu tenho que comer'. Aí você acaba comendo, né... é proibido, mas você come. Mas é muitas coisas Que eles falam Que não pode. 'Aí isso não pode, isso também não pode, isso não pode'. É muita coisa. É mais não do Que sim (E2).

...às vezes me entristece assim... porQue às vezes eu tô com uma vontade de... dá uma vontade tão de Querer comer alguma coisa e não pode porQue... Que nem líquido, às vezes dá aQuela vontade assim de tomar um refrigerante, uma latinha de $300 \mathrm{ml}$ (...) Então essas coisas de ficar manerando às vezes você cansa. Você pensa "Ah, vou tomar e deixa o Que for acontecer lá na má@uina acontecer (E3).

Os indivíduos com IRC sentem a necessidade de reafirmarem para si próprios Que, mesmo com as restrições, permanecem íntegros ${ }^{(18)}$. Tal Questão pode ser observada no discurso a seguir, Quando a entrevistada coloca Que apesar de ter sido difícil seguir a restrição hídrica no início do tratamento, esta já se tornou algo normal e que já faz parte do seu cotidiano.

Ah, a única dificuldade Que tem é Que você tá com vontade de comer e não pode (risos), mas a gente acostuma... difícil no começo? É superdifícil, você acha Que vai morrer porQue não vai poder beber água. Agora não faz diferença. Acostuma, acho Que com o tempo a gente acostuma com tudo porque isso daí, vamos dizer, é a vida da gente, né. Então você tem Que acostumar com aquilo (E6).

Ainda dentre as limitações tem-se a falta de lazer, importante para a manutenção da CDA, incluindo passeios, cinema ou Qualeuer outra atividade Que proporcione prazer e faça com Que o indivíduo esQueça por alguns momentos as dificuldades e preocupações ${ }^{(9)}$.

Não. Eu não saio de casa. É da minha casa-aqui, daQui-em casa... eu não saio pra canto nenhum (...) É só em casa. PorQue pra mim sair... pra ir na casa da minha irmã é morro e eu não consigo subir muito morro porque dói as perna. Pra casa da minha mãe pra descer é descida, mas pra subir já é subida. Então eu já não... nem me atrevo sair de casa. Fico mais em casa do que eu saio (E4).

A incapacidade para o trabalho também interfere na vida do indivíduo, já Que é muito difícil manter vínculos empregatícios formais, tanto pela rotina do tratamento, como pelas complicações e limitações físicas advindas com o problema renal. Tal situação provoca uma diminuição da auto-estima dos indivíduos Que passam a ser dependentes financeiramente e precisam, na maioria das vezes, do auxílio de um familiar ou pessoa próxima. A responsabilidade de manter a família é transferida para outra pessoa.

Você não pode trabalhar. Como é Que você vai trabalhar? Ninguém te dá emprego. Abrir mão que eu falo é assim... sua vida pára... sua vida pára, sua vida muda totalmente. Você não tem aQuela disposição que uma pessoa normal tem... Eu gostaria de trabalhar né... mas é muito difícil alguém dar emprego pra gente (E2).

Os vínculos informais acomodam melhor esses pacientes, pois eles podem escolher a atividade Que melhor se adapta, segundo suas deficiências e estado geral e, principalmente, horários e períodos mais flexíveis para o seu desenvolvimento ${ }^{(19)}$.

As diversas restrições e limitações resultam para o indivíduo em uma perda da sua autonomia, pois a sua vida passa a depender de um tratamento prolongado, doloroso, desgastante, porém, necessário. Tal Questão também está relacionada com a incapacidade para o trabalho, resultando em dependência financeira, e do próprio tratamento de hemodiálise Que torna o indivíduo dependente de uma máquina e de profissionais capacitados, além das limitações físicas Que impossibilitam as pessoas de realizarem atividades cotidianas, como limpeza da casa e fazer compras ${ }^{(20)}$.

...Quando a gente não tá doente a gente faz de tudo limpa a casa, anda, passeia, vai em supermercado, né. Você sai a hora que você Quer, cê vai onde você Quer, cê volta na hora Que você Quer e a gente agora não escolhe é nada, tem tudo na hora certa, né (E7).

A hemodiálise suscita sentimentos ambíguos de amor e ódio nos indivíduos Que precisam deste tratamento para sobreviver, pois ao mesmo tempo em Que garante a vida, torna a pessoa dependente de uma máquina, dependente da tecnologia. Há um simbolismo atribuído à hemodiálise, tratando a mesma como uma 
relação de "vida e morte", confessando Que a sobrevivência é possível pelo procedimento de hemodiálise.

... uma relação de vida, né... eu tô viva graças a hemodiálise (...) com todo esse sofrimento, com todas essas dificuldades, né... Que eu tenho... do jeito que eu tô porque pros outros pode ser Que assim... mas é... vinte e tantos anos ou vinte anos Que seja... é graças a hemodiálise, a máquina ou não... eu tô aQui, tem o testemunho, né. Se não fosse a hemodiálise nem sei o Que seria, se tava aQui ou não (...) não é tão assim ruim, ruim porQue tem os momentos assim... tem muitos momentos alegres e bons.. (E5).

\section{Domínio Ambiente Físico}

A rotina e tempo de permanência na sessão de hemodiálise foram identificados como fonte de demanda de atenção. Submeterse a uma rotina de hemodiálise em Que é necessário freqüentar o serviço três vezes por semana com duração em média de Quatro horas acarreta para a pessoa um desgaste físico e emocional. $\mathrm{O}$ próprio ambiente hospitalar foi tido como desgastante, além do ócio durante a sessão de hemodiálise em si.

...você vir pra cá três vezes por semana é desgastante, entendeu? O hospital é desgastante, é cansativo por mais que você fala fica sentada lá Quatro horas, mas não é assim. Você não pode fazer nada, não pode levantar, fica Quatro horas lá sentada ali, sabe. Então é desgastante, tem vez que você sai daqui nervosa, você não Quer papo, está com dor de cabeça (E2).

A rotina incessante resulta em uma monotonia, sendo difícil aceitar o fato de ter Que retornar em breve para uma nova sessão e assim por diante, contribuindo para o sentimento de desesperança e afirmando a cada sessão a sua dependência ao tratamento.

\section{Domínio Informação}

O acúmulo e a complexidade de informações interferem na compreensão do paciente Quanto ao seu problema de saúde e tratamento. A abordagem a esses pacientes, pelos profissionais de saúde, deve ser realizada de maneira a transmitir informações em uma linguagem acessível, principalmente ao se considerar a especificidade da linguagem técnica e nível de escolaridade do paciente. Uma informação complexa e inadequada pode resultar para a pessoa na dificuldade em compreender o processo de tratamento, o Que resultará em um aumento da CDA para atender às exigências do tratamento. Então, as informações devem ser transmitidas aos poucos e de forma clara, e o profissional de saúde deve se certificar do entendimento do paciente, auxiliando-o nesse aspecto.

... uma coisa Que me marcou foi Quando o médico falou pra mim Que eu tinha Que fazer hemodiálise. Pra mim foi um bicho de sete cabeças , né... porQue eu não... não sabia... nem sabia Que existia essa palavra. Aí eu peguei e fiquei com medo e falei Que não ia fazer não (...) Aí veio um médico, perguntava, me explicava, mas era uma coisa Que não entrava na minha cabeça (...) Aí ele me explicou três vezes pra mim entender, mas mesmo assim eu fiquei (...) meia com o pé atrás porque eles estavam falando difícil pra mim, estavam falando uma coisa Que eu não conhecia (E4).

\section{CONSIDERAÇÕES FINAIS}

Neste estudo, foi possível identificar as diferentes fontes de demanda de atenção a Que o indivíduo com IRC, em tratamento de hemodiálise, está exposto. Tais demandas podem resultar para a pessoa em um aumento da CDA para lidar com as exigências do tratamento e condução das atividades diárias, ou seja, o aumento da CDA resulta em uma diminuição da capacidade de concentração, sendo a mesma essencial para Que o indivíduo possa lidar com as adversidades emergidas do cotidiano e do tratamento de hemodiálise.

Para o enfermeiro, é importante conhecer tais fontes de demandas de atenção para buscar estratégias Que as minimizem. Adaptar-se a essa nova realidade não é um processo tran@üilo, e o profissional de saúde deve compreender e auxiliar o indivíduo, bem como sua família, neste caminho.

Cabe ressaltar Que as fontes de demandas identificadas neste estudo foram restritas a uma amostra feminina, não sendo possível inferir se também ocorrem com os indivíduos do sexo masculino. Acredita-se que muitas das fontes de demandas sejam semelhantes para ambos os sexos, mas para afirmar tal Questão faz-se necessária a elaboração de outros estudos.

\section{REFERÊNCIAS}

I. Sociedade Brasileira de Nefrologia. Censo - 2003/2004. [citado em: 29 jun 2006]. Disponível em: URL: http:// www.sbn.org.br/

2. Sociedade Brasileira de Nefrologia. Censo - 2005. [citado em: 29 jun 2006]. Disponível em: URL: http://www.sbn.org.br/

3. Riella MC. Patogenia e fisiopatologia das nefropatias: insuficiência renal crônica. In: Riella MC. Princípios de nefrologia e distúrbios hidroeletrolíticos. $3^{\text {a }}$ ed. Rio de Janeiro (RI): Guanabara Koogan; 1980. p. 360-401.

4. Lewis SM, Collier ICC, Heitkemper MM. Medical-surgical nursing: assessment and management of clinical problems. $4^{a}$ ed. New York (NY): Mosby; 1996.

5. Kaplan S, Kaplan, R. Cognition and environment: functioning in an uncertain world. Michigan (IL): Ulrich's; 1983.
6. Cimprich B. Attentional fatigue following breast cancer surgery. Res Nurs Health 1992; 15(3): 199-207.

7. Cimprich B. Development of an intervention to restore attention in cancer patients. Cancer Nurs 1993; 16(2): 83-92.

8. Cimprich B. Age and extend of surgery affect attention in women treated for breast cancer. Res Nurs Health 1998; 21 : 229-38.

9. Jansen DA, Cimprich B. Attentional impairment in persons with multiple sclerosis. I Neuroscience Nurs 1994; 26(2): 95- 102.

10. Lehto R, Cimprich B. Anxiety and directed attention in women awaiting breast cancer surgery. Oncology Nurs Forun 1999; 26 (4): 767-72.

11. Morse IM, Field PA. Qualitative research methods for health professionals. $2^{\text {nd }}$ ed. London (UK): Sage Publication; 1995. 
12. Santos SR. Métodos Qualitativos e Quantitativos na pesquisa biomédica. J Pediatria 1999; 75(6): 40 I-6.

13. Jansen DA, Keller ML. Identifying the attentional demands perceived by elderly people. Rehabilitation Nurs 1998; 23(I): 12-20.

14. Rew L., Bechtel D, Sapp A. Self-as-instrument in Qualitative research. Nurs Res 1993; 42(5):300-1.

15. D'andrea FF. Desenvolvimento da personalidade: enfoeue psicodinâmico. $12^{\text {a }}$ ed. Rio de Janeiro (RI): Bertrand Brasil; 1996.

16. Machado LRC, Car MR. A dialética da vida cotidiana de doentes com insuficiência renal crônica: o inevitável e o casual. Rev Esc Enferm USP 2003; 37(3): 27-35.
17. Frankl V. Em busca de sentido: um psicólogo no campo de concentração. $9^{\mathrm{a}}$ ed. São Leopoldo (RS): Sinodal/Nozes; 1999.

18. Barbosa JC, Aguillar OM, Boemer MR. O significado de conviver com a insuficiência renal crônica. Rev Bras Enferm 1999; 52(2): 293-302.

19. Campos CJG. A vivência do doente renal crônico em hemodiálise: significados atribuídos pelos pacientes [tese]. Campinas (SP): Faculdade de Ciências Médicas da Universidade Estadual de Campinas; 2002.

20. Martins MRI, Cesarino CB. Qualidade de vida de pessoas com doença renal crônica em tratamento hemodialítico. Rev Latinoam Enfermagem 2005; 13(5): 670-6. 